\title{
EVALUASI KEBIJAKAN, KELEMBAGAAN, INFRASTRUKTUR, APLIKASI, DAN PERENCANAAN E-GOVERNMENT DI PEMERINTAHAN KOTA BATU
}

\author{
Admaja Dwi Herlambang', Mochammad Chandra Saputra², Ridho Fadhlurrahman ${ }^{3}$ \\ 1,2,3 Jurusan Sistem Informasi, Fakultas Ilmu Komputer, Universitas Brawijaya \\ Email: ${ }^{1}$ herlambang@ub.ac.id, ${ }^{2}$ andra@ub.ac.id, ${ }^{3}$ frahman.ridho@gmail.com
}

(Naskah masuk: 01 Desember 2018, diterima untuk diterbitkan: 27 Mei 2019)

\begin{abstract}
Abstrak
Penelitian ini bertujuan untuk mengevaluasi penerapan e-government di Pemerintah Kota Batu dengan melakukan studi kasus di Dinas Komunikasi dan Informasi; Badan Perencanaan Pembangunan, Penelitian dan Pengembangan Daerah (Bapelitbangda); dan Dinas Pertanian Kota Batu. Penilaian dilakukan menggunakan kerangka kerja Pemeringkatan e-government Indonesia (PeGI) yang terdiri dari lima variabel pengukuran, yaitu kebijakan, kelembagaan, infrastruktur, aplikasi, dan perencanaan. Pendekatan penelitian yang digunakan adalah kualitatif dengan alat pengukuran berupa kuesioner, wawancara, dan observasi. Berdasarkan hasil penilaian, penerapan $e$ government di Dinas Kominfo, Bapelitbangda, dan Dinas Pertanian berada pada kategori Kurang. Hasil evaluasi merekomendasikan bahwa prioritas utama yang perlu diperbaiki dalam waktu dekat adalah variabel kebijakan, infrastruktur, dan perencanaan.
\end{abstract}

Kata kunci: e-government, PeGI, kebijakan, kelembagaan, infrastruktur, aplikasi, perencanaan

\section{EVALUATION OF E-GOVERNMENT POLICY, INSTITUTIONAL, INFRASTRUCTURE, APPLICATION, AND PLAN AT KOTA BATU GOVERNMENT}

\begin{abstract}
This study aims to evaluate the implementation of e-government in Kota Batu Government by conducting case studies at the Communications and Information Department; Regional Development Planning, Research and Development Department (Bapelitbangda); and Agriculture Department. The assessment was conducted using the Indonesian e-government Ranking Framework (PeGI) consisting of five measurement variables, namely policy, institutional, infrastructure, application, and planning. The research approach used is qualitative with questionnaires, interviews, and observations as measurement tools. Based on the assessment, the implementation of e-government in the Communications and Informatics Department, Bapelitbangda, and the Agriculture Department categorized as Less. The evaluation results recommend that the main priorities that need to be improved in the near future are policy, infrastructure, and planning variables.
\end{abstract}

Keywords: e-government, PeGI, policy, institutional, infrastructure, application, planning

\section{PENDAHULUAN}

Pengembangan e-government merupakan salah satu bentuk upaya pemerintah untuk menciptakan lingkungan birokrasi yang terbuka, bersih dan akuntabel dengan memanfaatkan teknologi informasi. Inisiatif pelaksanaan e-government dimulai dengan dikeluarkannya Instruksi Presiden nomor 6 tahun 2001 tentang Pengembangan dan Pendayagunaan Telematika (Telekomunikasi, Media dan Informatika). Dalam instruksi tersebut, dikatakan bahwa teknologi informasi harus digunakan oleh setiap instansi pemerintahan dalam rangka mendukung kegiatan pemerintahan. Kemudian pada tahun 2003 dikeluarkan Instruksi Presiden nomor 3 tahun 2003 Tentang Kebijakan Dan Strategi Nasional Pengembangan E-government, dimana dalam instruksi ini presiden mendorong agar setiap instansi pemerintah melakukan perumusan strategi $e$ government di lingkungan pemerintahannya masing masing. Dalam program reformasi birokrasi yang dicanangkan pemerintah melalui Peraturan Menteri Pemberdayaan Aparatur Negara dan Reformasi Birokrasi nomor 11 tahun 2011 tentang Kriteria Dan Ukuran Keberhasilan Reformasi Birokrasi, salah satu indikator keberhasilan dalam reformasi birokrasi adalah tersedianya e-government pada masing masing kementerian/lembaga dan pemerintah daerah, yang bertujuan agar terselenggaranya transparansi, akuntabilitas dan standarisasi proses penyelenggaraan pemerintah.

Pemerintah Kota Batu, sebagai bagian dari instansi pemerintahan Indonesia mulai melaksanakan perbaikan terhadap kinerja pemerintahannya sejalan 
dengan program reformasi birokrasi pemerintah, yaitu menata ulang, mengubah, memperbaiki dan menyempurnakan birokrasi agar menjadi lebih efisien, efektif dan produktif. Pada pengukuran Sistem Akuntabilitas Kinerja Instansi (SAKIP), selama 2 tahun Kota Batu menempati peringkat paling akhir dari 38 kota di Jawa Timur. Hasil pengukuran ini menunjukkan bahwa kinerja instansi pemerintah Kota Batu belum berjalan dengan maksimal sebagaimana yang diharapkan. Diantara penyebab belum maksimalnya kinerja instansi Pemerintah Kota Batu ini adalah masih lemahnya koordinasi antar elemen, belum adanya kesesuaian antara perencanaan dengan pelaksanaan di lapangan untuk beberapa agenda atau kegiatan dan belum detilnya penyusunan perencanaan dan anggaran. Untuk memperbaiki permasalahan ini, Pemerintah Kota Batu berupaya memaksimalkan penerapan $e$ government di setiap SOPD.

Untuk menilai penerapan e-government di Pemerintah Kota Batu, penelitian ini melakukan studi kasus di Dinas Kominfo Kota Batu, Bapelitbangda Kota Batu dan Dinas Pertanian Kota Batu, menggunakan kerangka kerja Pemeringkatan egovernment Indonesia (PeGI). Kerangka kerja ini dipilih karena PeGI merupakan kerangka kerja yang digunakan untuk menilai tingkat penerapan $e$ government di instansi-instansi pemerintah Indonesia, sesuai dengan salah satu tujuan PeGI untuk dapat memetakan penerapan e-government diseluruh instansi pemerintahan di Indonesia. Hasil penilaian digunakan untuk mengetahui capaian dan kelemahan SOPD yang diteliti dalam menerapkan $e$ government di Kota Batu.

\section{Kajian Pustaka}

Alusi dan Sensuse (2013) melakukan penilaian penerapan e-government di instansi pemerintah LAPAN untuk menyusun strategi penerapan $e$ government di masa depan menggunakan kerangka kerja PeGI. Hasil penilaian menunjukkan bahwa penerapan e-government di LAPAN berada pada kategori kurang. Strategi penerapan e-government kemudian disusun berdasarkan hasil penilaian tersebut.

Razak (2013) melakukan penilaian penerapan $e$ government di Kementerian Pertanian Republik Indonesia. Hasil penilaian menunjukkan penerapan $e$ government telah berada di kategori baik. Berdasarkan hasil penilaian, kemudian disusun strategi penerapan e-government untuk setiap variabel di dalam PeGI.

\section{Pemeringkatan e-government Indonesia}

Pemeringkatan e-government Indonesia (PeGI) merupakan kegiatan untuk melihat peta kondisi pemanfaatan teknologi informasi dan komunikasi di lembaga-lembaga pemerintah yang dilaksanakan oleh Kementerian Komunikasi dan Informasi (KEMKOMINFO) Republik Indonesia secara berkala. Kegiatan ini dilaksanakan agar terjadi peningkatan pemanfaatan teknologi informasi di seluruh instansi pemerintahan di Indonesia. PeGI bertujuan untuk menyediakan acuan bagi pengembangan dan pemanfaatan TIK di lingkungan pemerintah, memberikan dorongan bagi peningkatan pemanfaatan TIK di lingkungan pemerintah melalui evaluasi yang utuh, seimbang dan obyektif dan mendapatkan peta kondisi pemanfaatan TIK di lingkungan pemerintah secara nasional.

\section{METODOLOGI}

Alur penelitian digambarkan dalam Gambar 1. Penelitian dimulai dengan melakukan kajian teori untuk memperdalam wawasan tentang e-government dan bagaimana penerapannya telah dilakukan di instansi instansi Pemerintah Indonesia dan penerapan di Pemerintah Kota Batu khususnya. Kajian teori juga dilakukan untuk mempelajari produk produk hukum seperti peraturan atau instruksi berkaitan dengan pelaksanaan penerapan e-government.

Dilanjutkan dengan melakukan pengumpulan data menggunakan kuesioner PeGI. Kuesioner ini telah disusun oleh Direktorat APTIKA dalam Kemkominfo yang terdiri atas 29 pertanyaan. Narasumber dipilih menggunakan teknik purposive sampling dimana kuesioner diberikan kepada orang orang yang dianggap tahu dan memahami tata kerja dan pelaksanaan e-government di lingkungan kerja instansi yang akan diteliti. Setiap pertanyaan dalam kuesioner PeGI memiliki bobot penilaian yang sama dalam skala 1-4. Untuk memperjelas dan mendalami jawaban dari setiap pertanyaan yang telah diisi oleh narasumber, dilakukan wawancara kepada narasumber dan observasi di setiap SOPD yang diteliti. Kelompok hasil penilaian di tampilkan pada Tabel 2.

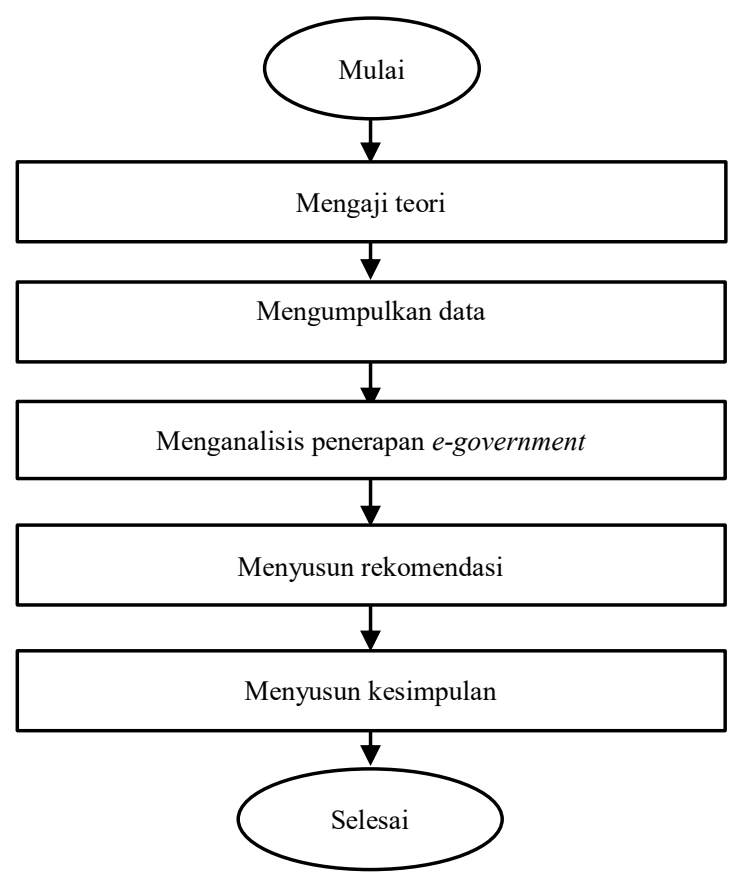

Gambar 1. Diagram Alir Penelitian 
Tabel 1 Kategori Hasil Penilaian PeGI

\begin{tabular}{cc}
\hline Nilai & Keterangan \\
& \\
\hline$\leq 4,00$ dan $\geq 3,60$ & Sangat Baik \\
\hline$<3,60$ dan $\geq 2,60$ & Baik \\
\hline$<2,60$ dan $\geq 1,60$ & Kurang \\
\hline$<1,60$ dan $\geq 1,00$ & Sangat Kurang \\
\hline
\end{tabular}

Sumber: www.pegi.layanan.go.id/tentang-pegi/

Setelah kuesioner selesai diisi oleh narasumber, kemudian dilakukan analisis dan penilaian penerapan e-government. Analisis dan penilaian dilakukan dengan mencocokkan hasil pengumpulan data dengan nilai yang terdapat didalam pedoman penilaian kerangka kerja PeGI. Setelah kegiatan penilaian selesai dilakukan, disusun rekomendasi untuk memperbaiki variabel variabel dengan kedaan penerapan e-government yang belum ideal jika dibandingkan dengan pedoman penilaian kerangka kerja PeGI. Rekomendasi perbaikan layanan $e$ government disusun berdasarkan kerangka kerja PeGI untuk mendapatkan kondisi penerapan $e$ government di kategori sangat baik.

\section{HASIL}

Secara keseluruhan, hasil penerapan egovernment di Dinas Kominfo Kota Batu masih berada di kategori kurang. Untuk Bapelitbangda Kota Batu hasil penilaian masih berada di kategori kurang dan pada Dinas Pertanian Kota Batu nilai penerapan e-government juga masih berada pada kategori kurang. Dari penilaian di tiga SOPD tersebut diketahui bahwa penerapan e-government masih kurang. Hasil penilaian setiap variabel di setiap SOPD yang diteliti diuraikan sebagai berikut.

\section{Dinas Kominfo}

Pada Variabel kebijakan, Dinas Kominfo mendapatkan nilai pada kategori baik. Variabel kelembagaan dengan kategori nilai baik, Variabel infrastruktur mendapatkan nilai pada kategori kurang, Variabel aplikasi dengan nilai pada kategori kurang dan Variabel perencanaan dengan kategori nilai baik.

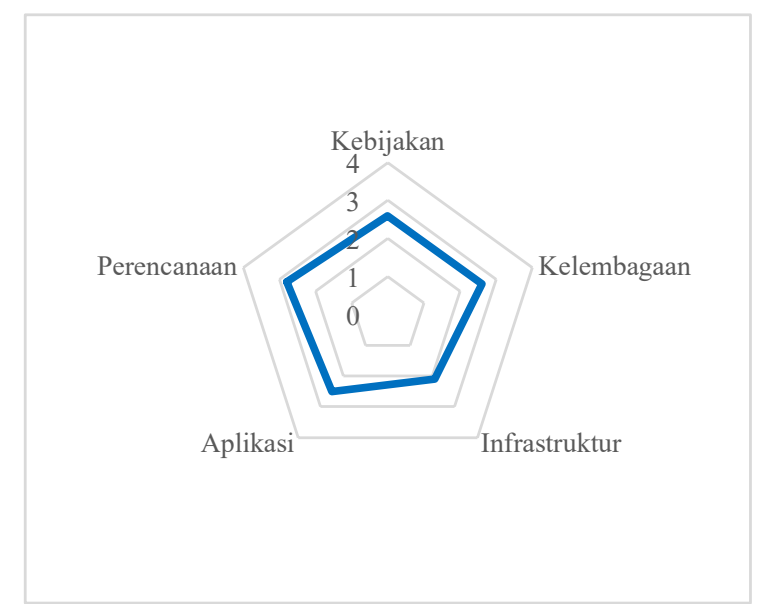

Gambar 2. Hasil Penilaian Dinas Kominfo

\section{Bapelitbangda}

Bapelitbangda pada Variabel kebijakan mendapatkan nilai di kategori sangat kurang. Variabel kelembagaan dengan kategori nilai kurang, Variabel infrastruktur mendapatkan nilai pada kategori kurang, Variabel aplikasi dengan nilai pada kategori kurang dan Variabel perencanaan dengan kategori nilai kurang.

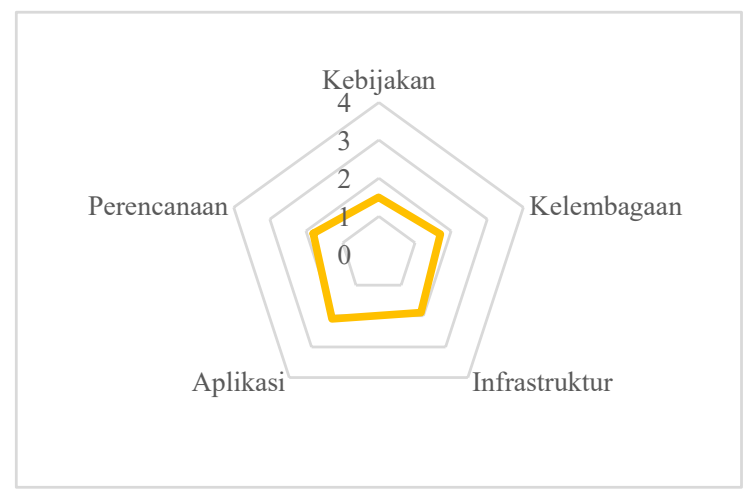

Gambar 3. Hasil Penilaian Bapelitbangda

\section{Dinas Pertanian}

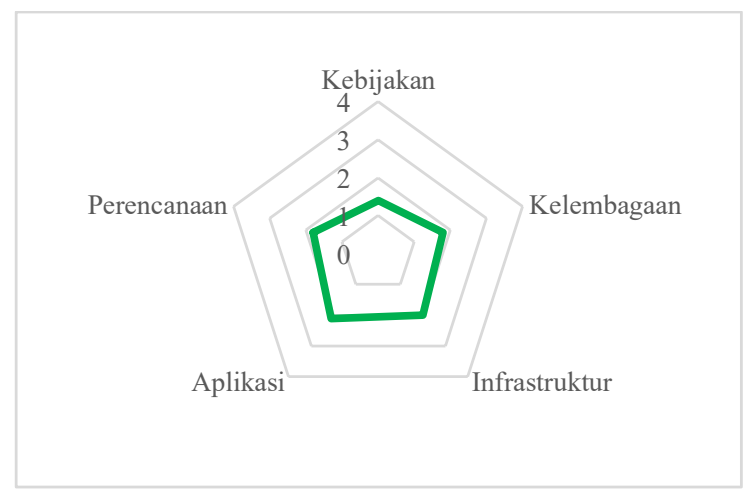

Gambar 4. Hasil Penilaian Dinas Pertanian

Pada Variabel kebijakan, Dinas Pertanian mendapatkan nilai pada kategori sangat kurang. Variabel kelembagaan dengan kategori nilai kurang, Variabel infrastruktur mendapatkan nilai pada kategori kurang, Variabel aplikasi dengan nilai pada kategori kurang dan Variabel perencanaan dengan kategori nilai kurang. Berdasarkan penilaian yang dilakukan, nilai untuk seluruh Variabel ditampilkan dalam Tabel 3.

\begin{tabular}{cccc}
\multicolumn{4}{c}{ Tabel 3 Hasil Penilaian Keseluruhan } \\
\hline Variabel & $\begin{array}{c}\text { Dinas } \\
\text { Kominfo }\end{array}$ & Bapelitbangda & $\begin{array}{c}\text { Dinas } \\
\text { Pertanian }\end{array}$ \\
\hline Kebijakan & 2,6 & 1,5 & 1,4 \\
\hline Kelembagaan & 2,6 & 1,7 & 1,8 \\
\hline Anfrastruktur & 2,1 & 1,9 & 2 \\
\hline Perencanaan & 2,8 & 2,1 & 2,1 \\
\hline
\end{tabular}




\section{PEMBAHASAN}

\subsection{Analisis Penerapan E-government}

Pembahasan penerapan e-government disetiap SOPD adalah sebagai berikut.

\section{Variabel Kebijakan}

Untuk penilaian pada Variabel kebijakan, Dinas Kominfo mendapatkan nilai dengan kategori baik, Sedangkan Dinas Pertanian dan Bapelitbangda mendapatkan penilaian pada kategori sangat kurang.

Dalam mendukung kegiatan pemerintahan di Dinas Kominfo, sudah ada kebijakan penerapan $e$ government yang terdapat di dalam Perwali No.78 Tahun 2018. Kebijakan ini juga didukung dengan adanya skala prioritas Dinas Kominfo, strategi penerapan, peraturan dan keputusan instansi. Namun, saat ini belum ada Rencana Induk yang berisi penyusunan strategi penerapan TIK secara menyeluruh. Pada Dinas Pertanian, saat ini belum memiliki kebijakan penerapan TIK yang dijalankan secara mandiri, kebanyakan kebijakan yang dijalankan merupakan arahan dari Dinas Kominfo atau lembaga lain yang secara vertikal berhubungan dengan Dinas Pertanian, seperti Dinas Pertanian dan Kementerian Pertanian RI. Begitu juga dengan penerapan TIK di lingkungan Bapelitbangda masih belum berjalan dengan baik. Kebijakan yang ada dapat berubah sewaktu waktu dan penyusunan kebijakan masih jarang mempertimbangkan kebutuhan TIK, sehingga penerapan kebijakan berkaitan dengan TIK belum dapat dilaksanakan dengan konsisten.

\section{Variabel Kelembagaan}

Pada variabel kelembagaan, Dinas Kominfo mendapatkan nilai dengan kategori baik. Namun, untuk Dinas Pertanian dan Bapelitbangda masih berada pada kategori kurang. Terkait dengan keberadaan struktur organisasi yang memiliki tugas dan fungsi berkaitan dengan TIK, Dinas Kominfo telah memiliki struktur organisasi yang jelas. Tugas pokok ini dijabarkan dalam Perwali No.86 Tahun 2016. Namun, saat ini belum ada prosedur kerja yang terdokumentasi dengan baku. Pada sektor SDM, ketersediaan SDM dengan latar belakang TIK masih kurang dan juga belum ada kegiatan peningkatan skill berkaitan dengan TIK di Dinas Kominfo. Di Bapelitbangda, saat ini belum memiliki struktur organisasi yang bertugas dalam pengelolaan dan pelaksanaan tugas berkaitan dengan TIK. Bapelitbangda juga belum memiliki prosedur kerja dan kecupukan SDM berkaitan dengan TIK yang masih kurang untuk masa depan. Untuk Dinas Pertanian, jika dilihat dari struktur organisasinya, belum ada bagian yang bertugas dalam pengelolaan TIK, karena saat ini Dinas Pertanian hanya mengikuti arahan Dinas Kominfo dalam urusan tersebut.

\section{Variabel Infrastruktur}

Penilaian pada variabel infrastruktur, baik Dinas Kominfo, Dinas Pertanian dan Bapelitbangda masih berada pada kategori penilaian kurang. Terdapat beberapa hal yang harus dibenahi dan dipenuhi dalam menunjang pelaksanaan penerapan TIK di lingkungan SOPD terkait, diantaranya pengembangan data center beserta aplikasi aplikasi penunjang dimana saat ini data center hanya berupa pengumpulan server server di satu tempat, kemudian perlu pembenahan dalam sistem keamanan karena belum ada penerapan strategi keamanan yang detail, pembuatan rencana pengelolaan dan mitigasi bencana dan manajemen pemeliharaan aset TIK serta belum adanya back up plan. Saat ini, pengelolaan infrastruktur TIK terpusat pada Dinas Kominfo.

\section{Variabel Aplikasi}

Pada variabel aplikasi, penilaian baik untuk Dinas Kominfo, Dinas Pertanian dan Bapelitbangda masih berada pada kategori kurang. Terdapat beberapa hal yang perlu dibenahi terkait dengan penilaian pada variabel ini, yaitu website yang masih bersifat statis dan belum ada dukungan interaktifitas dengan masyarakat seperti fitur penyampaian aspirasi, keluhan, kritik dan atau saran. Kemudian, belum ada kegiatan inventarisasi aplikasi yang dilakukan secara menyeluruh dan detail, dari data inventarisasi yang ada, informasi yang didapatkan baru sekedar data umum aplikasi, belum ada informasi apakah status aplikasi tersebut masih baik atau kritikal dan perlu perbaikan. Untuk aplikasi aplikasi fungsional seperti keuangan, manajemen umum, legislasi, kepegawaian dan pembangunan sudah digunakan dengan baik, karena $70 \%$ dari aplikasi tersebut merupakan aplikasi yang disediakan oleh pemerintah pusat.

\section{Variabel Perencanaan}

Untuk penilaian pada Variabel perencanaan, Dinas Kominfo berada pada kategori baik. Sedangkan Dinas Pertanian dan Bapelitbangda mendapatkan nilai pada kategori kurang. Saat ini, Dinas Kominfo sedang menjalankan rencana pengembangan TIK, berdasarkan Perwali no.78 tahun 2016 tentang Master Plan Batu Smart City, yang saat ini sedang dalam pengembangan tahap pertama. Sedangkan pada Dinas Pertanian dan Bapelitbangda, belum ada master plan yang digunakan sebagai dasar kebijakan penerapan TIK. Secara umum, dalam lingkup pengembangan $e$ government di Pemerintah Kota Batu, masih banyak hal yang perlu dibenahi, salah satunya dan yang menjadi inti dari perencanaan pengembangan $e$ government adalah belum adanya Rencana Induk TIK. Rencana Induk TIK perlu disusun agar pengelolaan dan penerapan TIK dapat dilakukan secara menyeluruh di seluruh SOPD Kota Batu. 


\subsection{Rekomendasi}

\section{Dinas Kominfo}

- Variabel kebijakan, rekomendasi yang diberikan adalah menjadikan visi dan misi sebagai landasan penerapan TIK, menyusun kebijakan yang baku berkaitan dengan TIK, memaksimalkan penerapan kebijakan TIK, membuat pedoman dan dokumentasi pelaksanaan kebijakan TIK, menyusun skala prioritas penerapan TIK dengan dokumentasi yang baik dan menyusun kebijakan manajemen risiko TIK.

- Variabel kelembagaan, rekomendasi yang diberikan adalah menyusun tugas dan fungsi TIK secara lengkap, menyusun prosedur kerja terkait TIK dengan lengkap, membuat perencanaan kebutuhan SDM saat ini dan yang akan datang dan menyusun program pengembangan skill SDM TIK.

- Variabel infrastruktur, rekomendasi yang diberikan adalah membangun data center dengan sesuai standar yang baik, kemudian membuat rencana mekanisme keamanan informasi data, yang dapat digunakan di seluruh SOPD. Kemudian menyusun perencanaan mitigasi dan pengelolaan bencana dengan dokumentasi yang baik, mengadakan mekanisme pemeliharaan TIK terjadwal, melakukan dokumentasi aset TIK secara rutin.

- Variabel aplikasi, rekomendasi yang diberikan adalah mengembangkan situs web yang dinamis dan mendukung interaktifitas dengan masyarakat, Menyusun SOP penggunaan setiap aplikasi dan melakukan kegiatan inventarisasi aplikasi TIK dengan rinci.

- Variabel perencanaan, rekomendasi yang diberikan adalah melakukan kegiatan perencanaan TIK dengan melibatkan seluruh stake holders, menyusun mekanisme perencanaan TIK dengan mengacu kepada visi dan misi instansi dan menyusun Rencana Induk TIK.

\section{Bapelitbangda dan Dinas Pertanian}

Berdasarkan hasil penilaian, baik Bapelitbangda maupun Dinas Pertanian mendapatkan nilai yang kurang lebih sama untuk setiap Variabel, sehingga diberikan rekomendasi yang sama, yaitu:

- Variabel kebijakan, rekomendasi yang diberikan adalah menjadikan visi misi instansi sebagai landasan dalam menyusun strategi penerapaan TIK, membuat strategi penerapan TIK khusus internal Bapelitbangdan dan Dinas Pertanian, memaksimalkan pelaksanaan penerapan kebijakan TIK, membuat peraturan penerapan TIK yang dilaksanakan dengan konsisten, mengeluarkan keputusan instansi, skala prioritas dan evaluasi secara rutin terkait penerapan TIK.
- Variabel kelembagaan, rekomendasi yang diberikan adalah mengembangkan struktur organisasi berkaitan dengan unit atau bagian pengelola TIK, menyusun tugas dan fungsi organisasi berkaitan dengan TIK secara lengkap, menyusun prosedur kerja berkaitan dengan penerapan TIK, membuat perencanaan kebutuhan SDM untuk saat ini dan masa depan, serta menyusun rencana pengembangan skill SDM berkaitan dengan TIK.

- Variabel infrastruktur, rekomendasi yang diberikan adalah menyusun rencana pengadaan fasilitas pendukung infrastruktur TIK dengan memperhatikan kebutuhan dan keamanan informasi data, menyusun mekanisme dan penjadwalan pemeliharaan aset TIK dan membuat dokumentasi daftar inventarisasi aset aset TIK secara rutin.

- Variabel aplikasi, rekomendasi yang diberikan adalah membentuk tim pengelola website yang menangani kebutuhan penyebaran informasi setiap SOPD dan menyusun SOP penggunaan aplikasi.

- Variabel perencanaan, rekomendasi yang diberikan adalah melakukan kegiatan perencanaan TIK dengan melibatan seluruh stake holder dan menyusun mekanisme perencanaan TIK yang mengacu kepada visi dan misi instansi.

\section{KESIMPULAN}

Hasil penilaian penerapan e-government di tiga Struktur Organisasi Perangkat Daerah (SOPD) Kota Batu menggunakan kerangka kerja PeGI di Dinas Kominfo, Bapelitbangda dan Dinas Pertanian Kota Batu, didapatkan simpulan bahwa hasil penilaian penerapan e-government menggunakan PeGI, baik Dinas Kominfo Dinas Pertanian dan Bapelitbangda mash berada pada kategori kurang,. Untuk melakukan perbaikan atas kualitas layanan e-government di tiga SOPD yang diteliti, disusun saran rekomendasi berdasarkan kerangka kerja PeGI untuk mendapatkan nilai pada kategori "sangat baik". Rekomendasi perbaikan untuk setiap SOPD yang diteliti dijabarkan ke dalam lima variabel, yaitu kebijakan, kelembagaan, infrastruktur, aplikasi, dan perencanaan.

Saran untuk penelitian selanjutnya adalah melakukan penilaian penerapan e-government pada SOPD lainnya di Pemerintah Kota Batu, sehingga hasil penilaian nantinya dapat digunakan untuk memetakan sejauh mana konsep e-government telah diterapkan di lingkungan Pemerintah Kota Batu. Penelitian selanjutnya juga dapat meneliti mengenai keterkaitan atau hubungan antara setiap Variabel dan sub Variabel yang ada pada kerangka kerja PeGI, sehingga kemudian dapat diketahui apakah nilai suatu Variabel dapat mempengaruhi nilai dari Variabel lainnya. 


\section{DAFTAR RUJUKAN}

AJI, A.P., 2017. Perwali Nomor 63 Tahun 2017 Sebagai Evaluator Sakip. [online], tersedia di: http://website.batukota.go.id/berita2280-perwali-nomer-63-tahun-2017-

sebagai-evaluator-sakip- [Diakses pada 5 Juni 2018]

ALUSI, F. \& SENSUSE, D.I., 2014. Penyusunan Strategi E-government Berbasis Kerangka Kerja Pemeringkatan E-government Indonesia (PEGI) Di Lembaga Penerbangan Dan Antariksa Nasional. Journal of Information Systems. Volume 10, Issue 1, April 2014. Universitas Indonesia. Depok.

KEMENTERIAN

APARATUR

PENDAYAGUNAAN

Peraturan Aparatur Negara Dan Reformasi Birokrasi No. 11 Tahun 2011 tentang Indikator Keberhasilan Reformasi Birokrasi. Jakarta.

PRESIDEN REPUBLIK INDONESIA, 2001. Instruksi Presiden Republik Indonesia Nomor 6 Tahun 2001 Tentang Telematika (Telekomunikasi, Media dan Informatika). Jakarta.

PRESIDEN REPUBLIK INDONESIA, 2003. Instruksi Presiden Republik Indonesia Nomor 3 Tahun 2003 Tentang Kebijakan Dan Strategi Nasional Pengembangan Egovernment. Instruksi Presiden. Jakarta.

RAZAK, A., 2013. Strategi Pengembangan Egovernment Menggunakan Kerangka Kerja Pemeringkatan E-government Indonesia (PeGI): Studi Kasus Kementerian Pertanian Indonesia. Tesis. Fakultas Ilmu Komputer. Universitas Indonesia. Depok. 